\title{
A exposição entre Curadoria e Públicos: problemas da Arte Contemporânea para a Ciência da Informação
}

Exposition between Curatorship and Publics: Contemporary Art problems for Information Science

Giulia Crippa

Livre Docente em Ciência da Informação pela Faculdade de Filosofia, Ciências e Letras de Ribeirão Preto da Universidade de São Paulo - FFCLRP/USP

Professora Titular do Curso de Biblioteconomia e Ciência da Informação da Faculdade de Filosofia, Ciências e Letras de Ribeirão Preto da Universidade de São Paulo - FFCLRP/USP.

E-mail: giuliac@ffclrp.usp.br

SCOTINI, Marco. Artecrazia: macchine espositive e governo dei pubblici. Roma: DeriveApprodi, 2016.

Um dos elementos que participa de maneira cada vez mais evidente ao surgimento do interesse dos públicos a eventos artísticos é a ênfase no evento expositivo.

A maior disponibilidade de tempo livre e a necessidade de animar as cidades com eventos disseminaram, ao longo dos últimos dois séculos, a tradição de exposições, em um primeiro momento artísticas, expandindo a tradição dos Salons parisienses para outros setores culturais e comerciais, como no caso das grandes exposições e feiras internacionais, para tornar a experiência acessível ao público de massa, modificando e refletindo sobre a "forma" do expor.

Surge, assim, a concepção de exposição como conjunto de objetos/obras que buscam narrativas unitárias, organizadas tanto por artistas bem como por profissionais que se dedicam à curadoria.

Estudar o tema das exposições torna-se relevante para o campo da Ciência da Informação, pois envolve muito mais que a síntese expográfica, na medida em que o que está em jogo são papeis de seleção, de organização, de mediação ligados a redes complexas de relacionamentos e de interesses discursivos que, acreditamos, precisam ser estudadas de maneira mais abrangente.

Por sua vez, a figura do curador se desenvolve como mediador entre as hipóteses de elaboração cultural dos objetos e realização no plano prático, enquanto ao mesmo tempo se ocupa da relevância teórica dessas operações. Seu papel, assim, não é unicamente o de historiador, nem de facilitador dos eventos, mas sim de coautor das exposições e das obras nelas contidas, principalmente quando age no campo das exposições artísticas. Marco Scotini, autor de Artecrazia: macchine espositive e governo dei pubblici (DeriveApprodi, 2016), é diretor artístico do FM Centro per l'Arte 
Contemporanea e do Departamento de Artes Visuais e Estudos Curatoriais da Nova Academia de Belas Artes (NABA) de Milão. Como curador, colaborou com várias instituições internacionais, entre as quais a Bienal de Veneza, e os Museus Van Abbemuseum, Reina Sofia, SALT, Castello di Rivoli e MIT. Disobedience Archive, sua exposição mais conhecida, foi apresentada em museus e espaços expositivos internacionais entre 2005 e 2015. Fundou a revista No Order: Art in a Post-Fordist Society pubblicada por Archive Books Berlino e, além de muitos ensaios, publicou o livro Politiche della memoria. Documentario e archivio (DeriveApprodi, 2014).

Protagonista de Artecrazia é o capitalismo e suas forças internas e opacas, que pertencem à globalização que, no entender do autor, apropriou-se do mundo da arte de maneira completa.

O livro de Scotini indaga o "estado da Arte" como se desenvolve após a crise financeira de 2008, apontando para a necessidade de uma crítica dos mecanismos que geram a ilusão da exposição enquanto espaço aberto, sem códigos fixados, alheio às hierarquias preestabelecidas e às hegemonias de empresas; analisa, também, o novo papel assumido pelos públicos de arte no âmbito das indústrias criativas e da economia dos eventos. Nas últimas décadas, foram muitas as experiências artísticas, expositivas e de museus que propuseram novas práticas e novas formas de relação com os espaços, as obras e o próprio público. A arte contemporânea e suas mediações se revelam, assim, capazes de medir seu impacto com o território do "político", tornando a crítica à economia e à sociedade neoliberal o lugar onde testar a liberdade artística. Bienais e públicos, medidas do valor e display, midiatização e ativismo colocam-se, dessa maneira, como centrais, na perspectiva do autor, transformando as funções, os papeis e o próprio estatuto da arte.

A palavra "artecracia" é, por Scotini, utilizado de maneira negativo, na medida em que remete à realização perfeita de uma estetização do político que encontra sua origem na última fase do movimento futurista, quando de sua maior adesão ao fascismo. O termo tornou-se o título de uma revista oficial, publicada entre 1934 e 1939, que buscava um conhecimento e uma inclusão explícitos no âmbito do regime de Mussolini. É, portanto, uma palavra que remete à arte utilizada pelo poder para obter formas de legitimação e, consequentemente, de exploração. O livro de Scotini trata do liberalismo levado ao extremo, através de novos monopólios, de grandes patrimônios nas mãos de poucos, de desigualdades sociais cada vez maiores. As relações econômicas desenham, de um lado, papeis tradicionais (o artista, o colecionador, o crítico) e, do outro, os lugares de legitimação desses papeis (os museus, os festivais, as bienais). Portanto, a arte coloca-se em uma posição bem distante da ideia romântica que lhe atribui um papel longe do mercado, avulsa de qualquer contexto. Pelo contrário: a arte deve sempre ser observada dentro de uma realidade socioeconômica e de suas formas 
de poder. Nesse sentido, o livro é uma crítica à Modernidade e à sua concepção de arte, que é a de algo capaz de humanizar o sistema de produção industrial e nos libertar dele, na medida em que se coloca como externa a ele.

Com base em uma clara e elaborada desconstrução do aparato social e econômico da "artecracia" e pelo percurso de diversas formações discursivas e interdisciplinares, depois da leitura dessa coletânea de ensaios, que compreende também entrevistas, desmascaram-se as relações perversas entre economia, poder e arte, e o leitor é levado a uma visão do atual sistema da arte que revela suas mistificações ideológicas, as retóricas que o legitimam, suas formas de condutas e seus diferenciais de liberdade e de subjetividade contemporâneas, que se apresentam expropriadas de qualquer potencialidade crítica ou subversiva.

Torna-se evidente como, através da máquina expositiva, se manifesta o cenário principal em que se concretiza o controle governamental e autoritário da arte e da cultura. É interessante destacar que o ponto de vista do autor sobre esse regime de visibilidade é produzido internamente ao próprio sistema da arte, enquanto se origina na prática do autor de curador e em suas contradições.

Artecrazia desenvolve uma crítica feroz à economia política da produção artística buscando, porém, ao mesmo tempo, os caminhos possíveis para encontrar uma capacidade afirmativa de experimentação estética e linguística das funções criativas e semióticas, para poder devolver o poder da imaginação política como espaço próprio da arte.

O aparecimento de ideias e conceitos ao longo do livro se condensa na entrevista final do livro, em que o autor responde a perguntas sobre Disobedience Archive, do qual foi curador. Disobedience Archive, construído com a colaboração direta de ativistas, artistas e film makers, depois de mais de dez anos de pesquisa e exposição nas principais instituições museais internacionais passou por várias transformações, agregando instâncias autônomas de insurgência e de conflito, arquivando uma multiplicidade de protestos, "focos de enunciação" das formas de desobediência social.

Disobedience Archive é um projeto que iniciou em 2005 e que foi exposto em importantes instituições do mundo inteiro. É constituído, em grande parte, por vídeos que indagam o ativismo artístico em suas varias declinações, desde as lutas sociais na Itália em 1977 até as revoltas mais recentes do Oriente Médio. O arquivo exposto busca reconstituir uma genealogia das muitas mobilizações antagonistas, com base nas modalidades de suas representações dentro do espaço artístico, analisando as problemáticas relacionadas à representação e às mídias, através das quais resulta que a História é sempre um exercício de poder que deve ser desmascarado e desmistificado. 
Para Scotini, o mesmo conceito vale também em relação à máquina expositiva e a seus públicos, em uma análise que segue as linhas de raciocínio da Institutional Critique das décadas de 1960 e 1970 e a leitura dedicada por Tony Bennet aos espaços dos museus (The birth of the museum, New York, York: Routledge, 1995). Scotini procura atualizar suas reflexões para o presente enquanto diretamente ligado a uma dimensão temporal bastante efémera dos eventos, como pode ser observado pela multiplicação das bienais realizadas pelo mundo nos últimos anos.

O estudo do trabalho de alguns artistas e cineastas (Peter Friedl, Alberto Grifi, Franco Vaccari, Clemens von Wedemeyer), de algumas exposições (Manifesta, Kassel) e o dialogo com alguns curadores (Li Xianting, Harald Szeeman) são, no livro de Scotini o ponto de partida de reflexões sobre a economia dos eventos (na seção Esposizioni), sobre os públicos da arte (na seção Pubblici) e sobre a relação entre cinema, política e espetáculo (na seção Schermi). Com efeito, a estrutura do livro são essas três seções, que se articulam tendo como eixo essa relação entre a máquina expositiva e o controle dos públicos. Desde a crítica do brand Manifesta, verdadeiro paradigma do projeto pósfordista dentro da União Europeia até os muitos episódios de "governo dos públicos", até o fenômeno da 'bienalização' (que melhor representa o sistema contemporâneo da arte), uma verdadeira máquina capaz de extrair valor e dinheiro de criar grandes números em termos de público e motor da indústria do turismo e do marketing urbano, dentro da lógica da economia do acontecimento. As bienais se tornaram, para o autor, essa máquina governamental perfeita: com suas promessas de experimentação ou de criatividade, promovem comportamentos e condutas, também através de uma forma de acumulação e monetarização do tempo e da sociabilidade, que não cabe mais no valor de uso nem no valor de troca, mas se torna o "valor de exposição": os públicos entregam-se, em uma forma de servidão voluntária a procedimentos de governance e dependência, tornando-se os novos trabalhadores nos tempos da "artecracia". Walter Benjamin definiu Ausstellungswert, ou seja, "valor de exposição" o valor da coisa que "torna-se proporcional ao nível de sua visibilidade, tanto que não pode mais ser reconduzido integralmente ao seu caráter intrínseco e à sua utilidade (valor de uso), nem à relação de força-trabalho entre o sistema de produção (valor de troca). Esse excedente, que torna algo em sua essência "alguma coisa que se mostra", "alguma coisa que se oferece aos olhares", é o que caracteriza a nova condição dos objetos e dos homens na época do capitalismo realizado" (Scotini, 2016. p. 59). Complexas tecnologias de poder uniformam as formas de vida e os comportamentos sociais: não somente as coisas podem ser reproduzidas e registradas, mas também, e acima de tudo, as pessoas, em formas de subserviência ao poder. Trata-se dos públicos e dos atores da "artecracia", distantes da possibilidade, para usar o termo de Jacques Rancière, de serem espectadores emancipados. Os processos existentes de enunciação e distribuição de papeis (o artista, 
o colecionador, o crítico, etc.) e os dispositivos de governance (isso é, os lugares de legitimação desses papeis: museus, festivais, Bienais etc.) são submetidos aos processos do mercado e à dimensão do capitalismo global.

"Não se trata mais de registrar o estado de subordinação da política à economia financeira. É necessário entender por que [...] a política (enquanto experiência, promessa, transformação) ou, melhor, sua "imagem" tornou-se o brand por excelência da máquina expositiva: o próprio motor, basicamente, da valorização capitalista e da exploração das indústrias criativas" (Scotini, 2016, p. $35)$.

Artecrazia segue, em sua estrutura, as formas de luta e de antagonismo contra o capitalismo financeiro, como os vários Occupy (no livro, veja-se o ensaio L'arte ostaggio della finanza: Occupy Whitney Museum), e a obra discute os efeitos de uma nova "democracia da criação", do capitalismo cognitivo e de suas formas de apropriação.

No pós-fordismo o tempo do trabalho invade a vida inteira. Para Scotini, "não somente é impossível preservar uma distinção rígida entre produção intelectual, ação política e cultura: é até impensável distinguir o trabalho do resto da atividade humana. No regime fordista, o intelecto permanecia fora do ciclo produtivo, no pós-fordismo atual trabalho e não trabalho desenvolvem uma mesma produtividade fundamentada no exercício de faculdades humanas genéricas, como a linguagem, os sentimentos, a sociabilidade, a estética etc.” (Scotini, 2016, p. 147).

Há umas perguntas fundamentais que permeiam o livro inteiro: ainda é possível uma forma de imaginação política? Como encontrar formas de recusa? Onde encontrar as rotas de fuga? Que controle podem ter artistas e públicos sobre as máquinas expositivas contemporâneas? Enfim: como quebrar o regime da "artecracia"? 